\title{
Selective CD28 blockade attenuates CTLA-4-dependent CD8+ memory T cell effector function and prolongs graft survival
}

\author{
Danya Liu, I. Raul Badell, and Mandy L. Ford \\ Department of Surgery and Emory Transplant Center, Emory University, Atlanta, Georgia, USA.
}

Memory T cells pose a significant problem to successful therapeutic control of unwanted immune responses during autoimmunity and transplantation, as they are differentially controlled by cosignaling receptors such as CD28 and CTLA-4. Treatment with abatacept and belatacept impede CD28 signaling by binding to CD80 and CD86, but they also have the unintended consequence of blocking the ligands for CTLA-4, a process that may inadvertently boost effector responses. Here, we show that a potentially novel anti-CD28 domain antibody (dAb) that selectively blocks CD28 but preserves CTLA-4 coinhibition confers improved allograft survival in sensitized recipients as compared with CTLA-4 Ig. However, both CTLA-4 Ig and anti-CD28 dAb similarly and significantly reduced the accumulation of donor-reactive $\mathrm{CD}^{+}$memory $\mathrm{T}$ cells, demonstrating that regulation of the expansion of CD8 ${ }^{+}$memory $T$ cell populations is controlled in part by CD28 signals and is not significantly impacted by CTLA-4. In contrast, selective CD28 blockade was superior to CTLA-4 Ig in inhibiting IFN- $\gamma$, TNF, and IL-2 production by $\mathrm{CD}^{+}$memory $\mathrm{T}$ cells, which in turn resulted in reduced recruitment of innate CD11b+ monocytes into allografts. Importantly, this superiority was CTLA-4 dependent, demonstrating that effector function of $\mathrm{CD8}^{+}$memory $\mathrm{T}$ cells is regulated by the balance of CD28 and CTLA-4 signaling.

Conflict of interest: The authors have declared that no conflict of interest exists.

Submitted: July 18, 2017 Accepted: November 28, 2017 Published: January 11, 2018

Reference information: JCI Insight. 2018;3(1):e96378. https:// doi.org/10.1172/ji.insight.96378.

\section{Introduction}

Belatacept, the first new therapy approved for immunosuppression in solid organ transplantation in 2 decades, offers a significant benefit to transplant recipients in that it confers a $43 \%$ reduction in the risk of patient death or graft loss after 7 years as compared with a calcineurin inhibitor-based regimen (1). However, belatacept in its current form carries a significantly increased risk of acute rejection as compared with calcineurin inhibitors (2), a fact that has limited its uptake in the clinical transplant community and markedly limited patient access to the opportunity for better long-term outcomes. One aspect thought to contribute to belatacept-resistant rejection is the presence of donor-reactive memory $\mathrm{T}$ cells in some transplant recipients $(3,4)$. Donor-reactive memory $\mathrm{T}$ cells can arise through prior transplantation, transfusion, pregnancy, or a process termed heterologous immunity, in which microbe-elicited $\mathrm{T}$ cells cross react with alloantigen (5). Importantly, memory $\mathrm{T}$ cells exhibit altered (but not eliminated) requirements for CD28-mediated costimulation during activation as compared with naive $\mathrm{T}$ cells (6), potentially rendering them less susceptible to the effects of belatacept-based immunosuppression. Indeed, both seminal and more recent studies in murine and nonhuman primate (NHP) transplant models and in vitro studies using human samples have identified donor-reactive $\mathrm{CD} 8^{+}$memory $\mathrm{T}$ cells as a dominant factor mediating costimulation blockade-resistant rejection (7-19). As approximately $40 \%$ of patients on the kidney transplant wait list are sensitized $(20,21)$, investigating novel ways to control donor-reactive memory $\mathrm{T}$ cell responses in transplantation remains an important goal.

It has been postulated that the memory $\mathrm{T}$ cell subset underlying belatacept-resistant rejection is the population of $\mathrm{CD} 28^{\text {null }} \mathrm{T}$ cells that arise in aged individuals and those with chronic diseases (22), including chronic kidney disease that precedes renal transplantation (23). This hypothesis is based on the fact that CD28 null cells produced inflammatory cytokines in a belatacept-independent manner in in vitro studies (19), confirming the expectation that they would not be affected by belatacept, given their CD28 $8^{\text {null }}$ status. However, CD28 $8^{\text {null }}$ cells are also more terminally differentiated, and it is not known whether they are capable of waging a rejection response in vivo. Along these lines, we recently showed that patients who went 
on to experience acute rejection on belatacept actually possessed increased frequencies of CD28 ${ }^{\text {hi }}$ memory $\mathrm{T}$ cells relative to those who did not experience rejection (24), suggesting that it is in fact a CD28 $8^{+}$memory $\mathrm{T}$ cell population that underlies belatacept-resistant rejection. If these cells are reliant on CD28 signals for optimal activation, why do they fail to be controlled in the setting of belatacept therapy? It is important to consider that treatment with abatacept and belatacept impede CD28 signaling by binding to CD80 and CD86, but also have the unintended consequence of blocking the ligands for CTLA-4 (25), which is highly expressed on memory $\mathrm{T}$ cells following secondary rechallenge.

The effects of CTLA-4 coinhibition on memory T cells are less well studied. In general, it is well known that there are both extrinsic and intrinsic mechanisms of CTLA-4-mediated coinhibition. CTLA4 can function in an extrinsic manner to suppress immune responses by binding to and pulling CD80/ CD86 from the surface of antigen-presenting cell (APC), thus limiting the amount of ligand available for CD28-mediated costimulation of neighboring cells (26-28). On the other hand, the observation that CTLA-4 binds intracellularly to phosphatases PP2A and SHP-2 and results in changes in gene expression (29) indicates that CTLA-4 also initiates specific signaling pathways in a cell-intrinsic manner. Further, CTLA-4 coinhibitory signals have been observed to impact CD28 $8^{\text {null }} \mathrm{T}$ cells in humans (30), suggesting again that cell-intrinsic coinhibitory signaling can occur. A study in which $\mathrm{CD} 4^{+} \mathrm{CD} 28^{\text {null }}$ and $\mathrm{CD} 8^{+} \mathrm{CD}$ $28^{\text {null }} \mathrm{T}$ cells were treated with CTLA-4 Ig revealed that blockade of CTLA-4 ligation resulted in increased memory T cell apoptosis/activation-induced cell death (30). The report went on to show that the apoptosis protection conferred by CTLA-4 ligation (in the absence of CTLA-4 Ig) was mediated in a cell-intrinsic manner by PI3K-dependent Akt phosphorylation, which in turn led to an increase in Bcl-2 expression and inhibition of the proapoptotic molecule Bad.

In light of these possibilities, we sought to determine the effect of a selective CD28 blocker in an experimental model of transplantation in which rejection is mediated by donor-reactive memory $\mathrm{CD} 8^{+} \mathrm{T}$ cells (31). Previous studies have examined the impact of selective CD28 blockers in both mouse and NHP models of transplantation and autoimmunity (32-37). For example, FR104, an antagonist anti-CD28 monovalent Fab' antibody, has been shown to prevent alloimmunization and prolong graft survival $(38,39)$. These effects were CTLA- 4 dependent and involved the promotion of Foxp3 ${ }^{+}$regulatory $\mathrm{T}$ cell responses following transplantation $(36,40)$. Here, we used a potentially novel anti-CD28 domain antibody is an Fc-devoid CD28-specific single chain $\mathrm{F}_{\mathrm{V}}$ domain generated using a $\mathrm{V} \kappa$ phage display library that specifically binds to and blocks CD28 signaling, leaving CTLA-4 coinhibition intact (41). Results revealed that selective CD28 blockade was superior to CTLA-4 Ig in preventing graft rejection mediated by memory $\mathrm{CD}^{+} \mathrm{T}$ cells, suggesting that memory $\mathrm{CD} 8^{+} \mathrm{T}$ cells are modulated by the balance of CD28 and CTLA-4 cosignaling. Interestingly, however, both CTLA-4 Ig and anti-CD28 dAb similarly reduced accumulation of secondary effectors derived from memory $\mathrm{CD} 8^{+} \mathrm{T}$ cells, suggesting that $\mathrm{CD} 28$ primarily controls the ability of $\mathrm{CD}^{+}$memory $\mathrm{T}$ cell populations to expand (with CTLA- 4 playing a minimal role). In contrast, selective CD28 blockade better controlled memory CD8 ${ }^{+} \mathrm{T}$ cell cytokine secretion in a CTLA-4-dependent manner as compared with CTLA-4 Ig, implicating CTLA-4 coinhibitory signals as necessary for the control of cytokine secretion in $\mathrm{CD}^{+}$secondary effectors. Overall, these data suggest that anti-CD28 domain antibodies might have a significant advantage in controlling the effector function of secondary $\mathrm{CD}^{+} \mathrm{T}$ cell responses in transplant recipients.

\section{Results}

Selective CD28 blockade more potently attenuates memory T cell-mediated graft rejection relative to CTLA-4 Ig. To begin to investigate the potential detrimental effect of blocking CTLA- 4 coinhibitory signals on CD ${ }^{+}$ memory $\mathrm{T}$ cells during transplantation, we first investigated the kinetics of CTLA-4 expression on memory vs. naive T cells. Naive or memory OVA-specific OT-I T cells (generated in vitro by antigen exposure followed by rest in IL-15-containing media as described by van der Windt et al.; ref. 42) were stimulated with peptide-loaded APC, and T cells were stained intracellularly for CTLA-4 expression at the indicated time points. Unlike naive $\mathrm{CD} 8^{+} \mathrm{T}$ cells, which did not demonstrate appreciable CTLA-4 expression until 24 hours after stimulation, memory $\mathrm{CD}^{+} \mathrm{T}$ cells significantly upregulated CTLA- 4 expression by just 2 hours after stimulation (Figure 1A). This upregulation was maintained on memory $\mathrm{CD}^{+} \mathrm{T}$ cells for at least 48 hours (Figure 1B). These data generated using in vitro-primed memory CD ${ }^{+} \mathrm{T}$ cells were confirmed using in vivo-primed memory $\mathrm{CD} 8^{+} \mathrm{T}$ cells (Supplemental Figure 1; supplemental material available online with this article; https://doi.org/10.1172/jci.insight.96378DS1), in that polyclonal endogenous CD $44^{\text {hi }} C D 8^{+} \mathrm{T}$ 
A

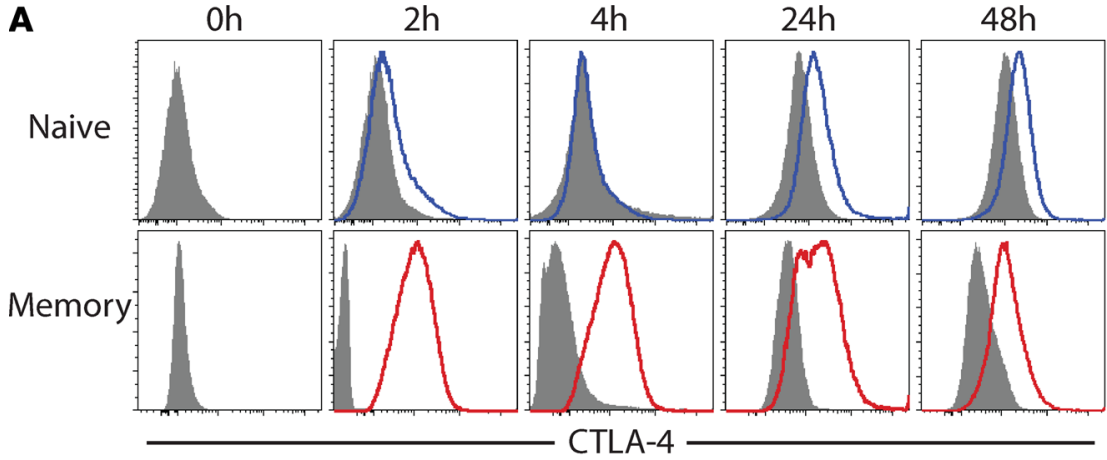

B

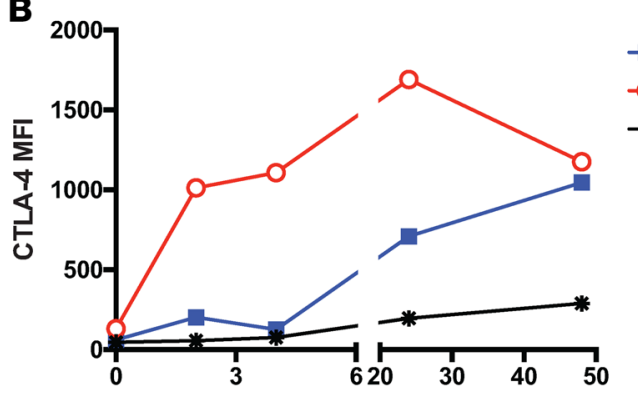

Hours Post Stimulation

D

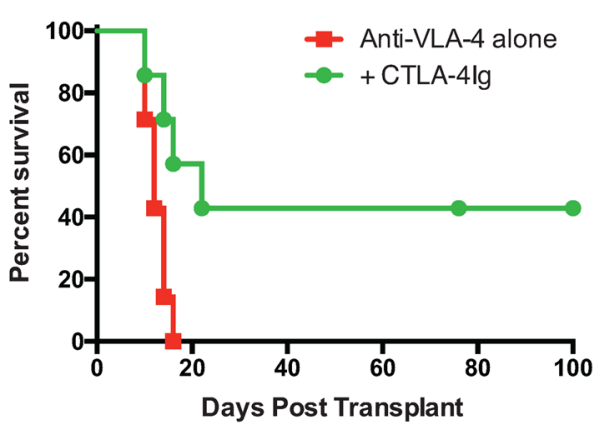

F

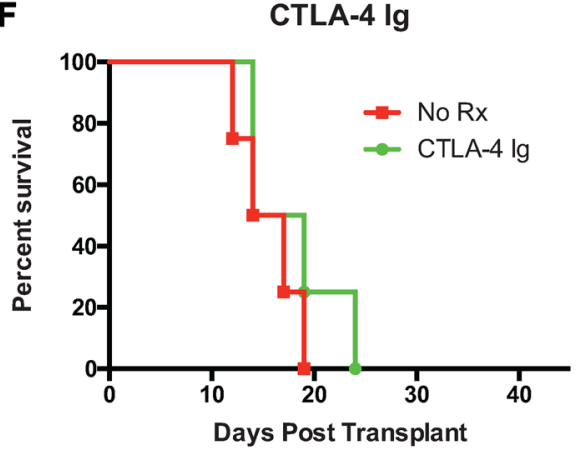

C
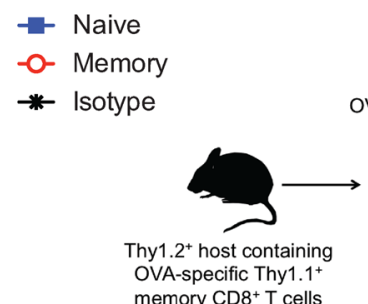

OVA-expressing skin graft

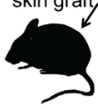

Thy $1.2^{+}$host containing
OVA-specific Thy $1.1^{+}$ memory $\mathrm{CD}^{+} \mathrm{T}$ cells

\section{E \\ E}

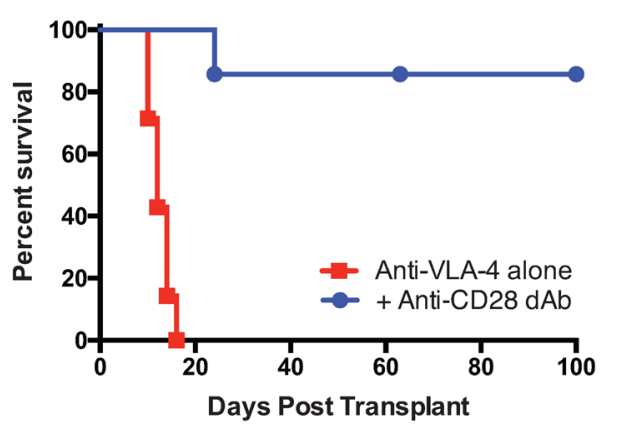

G

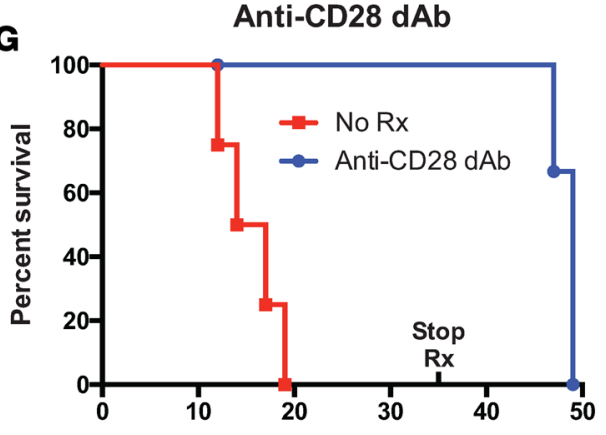

Days Post Transplant
Figure 1. Selective CD28 blockade more potently attenuates memory T cell-mediated graft rejection relative to CTLA-4

Ig. (A and $\mathbf{B})$ Naive or memory OVA-specific OT-I T cells ( $1 x$ $10^{6}$ cells; generated in vitro by antigen exposure followed by rest in IL-15-containing media as described ref. 42) were stimulated with B6 splenocytes and $10 \mathrm{nM}$ SIINFEKL peptide for $0,2,4,24$, or 48 hours. CD8 ${ }^{+} T$ cells were stained intracellularly for CTLA-4 (filled histograms indicate isotype control). (B) CTLA-4 MFI on naive and memory $T$ cells over time. Data are representative of 3 independent experiments. (C) Experimental design in which $1 \times 10^{4}$ Thy $1.1^{+}$OT-I T cells are adoptively transferred into naive B6 Thy 1.2 hosts and infected with Listeria-OVA as described in Methods in order to generate recipients containing memory OT-I T cells. On day 30 after infection, mice received an OVA-expressing skin graft and were treated with $200 \mu \mathrm{g}$ CTLA-4 Ig or $100 \mu \mathrm{g}$ anti-CD28 $\mathrm{dAb}$ (both in the presence of $250 \mu \mathrm{g}$ anti-VLA-4) on days $0,2,4$, and 6 after transplant. ( $D$ and $\mathbf{E}$ ) Graft survival curves showing accelerated rejection in animals treated with CTLA-4 Ig (D) relative to those treated with anti-CD28 dAb (E). Data are cumulative results of $n=$ 8 mice/group from 2 independent experiments. (F and $\mathbf{G})$ Recipients were primed with OVA-expressing skin grafts, allowed to reject, and regrafted on the contralateral torso on week 10 . Animals were treated with $200 \mu \mathrm{g}$ CTLA-4 Ig (F) or 100 $\mu \mathrm{g}$ anti-CD28 dAb (G) on days $0,2,4$, and 6 and then weekly until day 35. $n=4$ mice/group. $\mathrm{dAb}$, domain antibody.

cells upregulated CTLA-4 faster and for longer than did CD $44^{10} \mathrm{CD} 8^{+} \mathrm{T}$ cells following ex vivo restimulation with PMA/ionomycin (Supplemental Figure 1A). Similarly, Thy $1.1^{+}$memory OT-I T cells that were primed in vivo with Listeria-OVA exhibit increased and more sustained upregulation of CTLA-4 than did Thy $1.1^{-} \mathrm{CD}^{+} \mathrm{T}$ cells following ex vivo restimulation (Supplemental Figure $1 \mathrm{~B}$ ). These data therefore suggest that CTLA-4 may be functional at earlier time points on memory vs. naive T cells, and thus that blocking this coinhibitory function may serve to enhance $\mathrm{CD} 8^{+}$memory $\mathrm{T}$ cell responses during transplantation. 
A

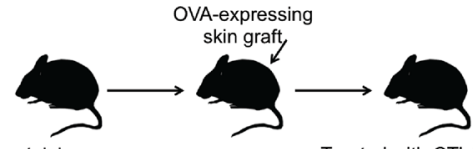

Thy $1.2^{+}$host containing OVA-specific Thy $1.1^{+}$memory $\mathrm{CD}^{+} \mathrm{T}$ cells

B

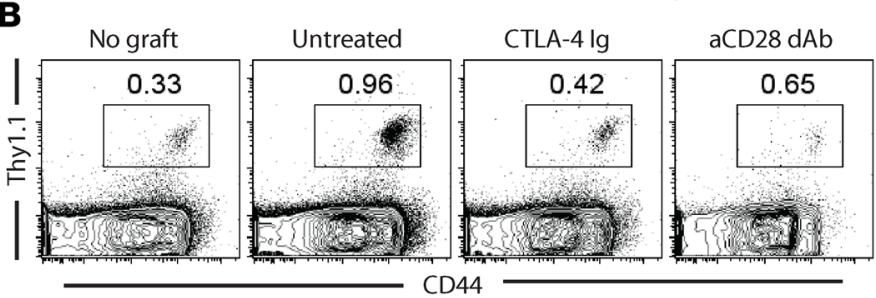

E

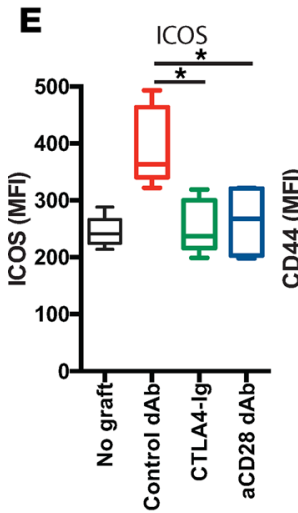

CD44

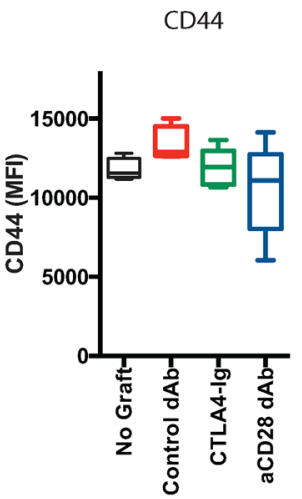

Treated with CTLA-4 Ig OR anti-CD28 $\mathrm{dAb}$
on days $0,2,4,6$
$\mathbf{F}$

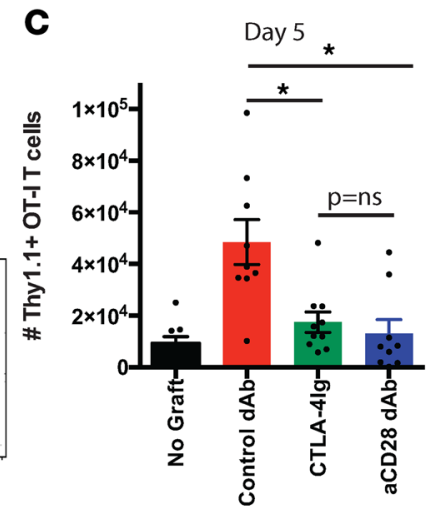

CD62L

Figure 2. Selective CD28 blockade more potently attenuates the accumulation of donor-reactive $\mathrm{CD}^{+} \mathrm{T}$ cells following transplantation as compared with CTLA-4 Ig. (A) Thy1.1+ OT-I T cells $\left(1 \times 10^{4}\right)$ were adoptively transferred into naive B6 Thy1.2 hosts and infected with Listeria-OVA to generate recipients containing memory OT-I T cells. On day 30 after infection, mice received an OVA-expressing skin graft and were treated with $200 \mu \mathrm{g}$ CTLA-4 Ig or $100 \mu \mathrm{g}$ anti-CD28 $\mathrm{dAb}$ on days $0,2,4$, and 6 after transplant. Animals were sacrificed on days 5 or 10 after transplant and graft-draining LN were harvested; the number of Thy $1.1^{+}$CD8 $8^{+}$T cells was quantified in (B) representative flow cytometry plots and ( $C$ and $\mathbf{D}$ ) summary data of absolute number of $C D 8^{+}$Thy1.1 $1^{+} T$ cells per draining node on day 5 (C) and day 10 (D). (E) MFI of ICOS, CD44, and CD62L expression on CD8 ${ }^{+}$Thy $1.1^{+}$T cells isolated from LN of mice in the indicated groups. Box and whisker plots show the median value. Boxes represent the 25th and 75th percentile, and whiskers depict the minimum and maximum values. Data shown in C-E are representative of data of 3 independent experiments with a total of 10-15 mice per group. (F) Endogenous OVA-specific CD8 ${ }^{+} T$ cell responses were measured on day 5 after transplant in the spleen in mice treated as above with either CTLA-4 Ig or anti-CD28 dAb (or left untreated). BrdU was administered on days 2 and 4 as described in Methods, and data shown are gated on CD8 ${ }^{+}$Thy1.1- splenocytes. (C) Summary data from $\mathbf{F}$ depicting $n=5$ mice per group. Experiment shown is representative of 2 independent experiments with a total of $9-10$ mice per group. ${ }^{*} P<0.0505$ by 1 -way ANOVA. dAb, domain antibody.

In order to test this hypothesis, we compared $\mathrm{CD} 8^{+}$memory $\mathrm{T}$ cell-mediated graft rejection in mice treated with CTLA-4 Ig, in which both CD28 and CTLA-4 are blocked, to mice treated with a selective CD28 domain antibody that blocks CD28 signals but leaves CTLA- 4 coinhibitory function intact. To generate mice that contained memory $\mathrm{CD} 8^{+} \mathrm{T}$ cells specific for their graft, we transferred $1 \times 10^{4}$ Thy $1.1^{+}$congenic OT-I T cells into naive Thy $1.2^{+}$B6 mice and infected them with OVA-expressing Listeria. As we have previously published, antigen-specific $\mathrm{T}$ cell responses peaked at day 10 and formed a detectable population of memory $\mathrm{CD} 8^{+} \mathrm{T}$ cells by day 30 (ref. 31 and data not shown). Skin graft rejection in this model is dependent on donor-reactive Thy $1.1^{+}$memory $\mathrm{CD} 8^{+} \mathrm{T}$ cells because administration of an anti-Thy1.1-depleting antibody eliminated the rejection response (31). On day 30 after infection, animals were challenged with an OVA-expressing skin graft and treated with immunosuppressive regimens consisting of an integrin blocker (anti-VLA-4) combined with either CTLA-4 Ig or anti-CD28 dAb (Figure 1C). Anti-VLA-4 has been previously shown to be synergistic in inhibiting memory $\mathrm{CD} 8^{+} \mathrm{T}$ cell-mediated graft rejection when combined with CTLA-4 Ig and anti-CD154 (43). Animals receiving the CTLA-4 Ig-based immunosuppression rejected their grafts with an MST of 22 days (Figure 1D), while those animals that received the anti-CD28 dAb-based immunosuppression experienced significantly prolonged allograft survival (MST undefined, $>100$ days; Figure 1E).

Because the above model of pathogen-elicited donor reactivity required the addition of an integrin antagonist in order to achieve therapeutic efficacy using either CTLA-4 Ig or anti-CD28 dAb, we next employed a model in which recipients containing Thy $1.1^{+}$congenic OT-I T cells were sensitized via an 
OVA-expressing skin graft. Recipients were allowed to reject and were then regrafted with an OVA skin graft on day 30 and treated with either PBS, CTLA-4 Ig, or anti-CD28 dAb alone as described in Methods. In this model using CD28 blockade monotherapy, we observed a significant increase in graft survival time for sensitized recipients treated with anti-CD28 dAb (MST 49 days) over untreated recipients (MST 15.5 days) ( $P=0.0147$; Figure $1 \mathrm{~F}$ ), but not for those treated with CTLA-4 Ig (MST 16.5 days; Figure 1G).

Selective CD28 blockade and CTLA-4 Ig similarly attenuate the accumulation of donor-reactive CD $8^{+} T$ cells following transplantation. In order to better understand why selective CD28 blockade resulted in attenuated $\mathrm{CD}^{+}$memory $\mathrm{T}$ cell-mediated rejection, we analyzed donor-reactive $\mathrm{CD} 8^{+}$memory $\mathrm{T}$ cell responses in these animals at day 5 following skin transplantation (Figure 2A). Draining lymph nodes (LN) were harvested, and flow cytometric analyses revealed that, while mice that contained graft-reactive $\mathrm{CD} 8^{+}$memory $\mathrm{T}$ cells and that did not receive a skin graft challenge contained low numbers of $\mathrm{CD}^{+}$memory $\mathrm{T}$ cells, those numbers were significantly increased in animals that received an OVA-expressing skin graft challenge (Figure 2, B and C). Importantly, memory $\mathrm{T}$ cell frequencies were significantly reduced in animals that received a skin graft challenge and were treated with CTLA-4 Ig relative to untreated skin graft-challenge recipients (Figure $2 \mathrm{C}$ ). Interestingly, and in contrast to what we observed with naive $\mathrm{CD}^{+} \mathrm{T}$ cells (41), selective CD28 blockade did not result in a further reduction in the number of $\mathrm{CD}^{+}$memory $\mathrm{T}$ cells isolated from the draining nodes of these recipients (Figure 2C). Similar findings were observed in the spleen (data not shown) and at an additional time point at day 10 after transplant when the recall response had contracted significantly (Figure 2D). Further, expression of the T cell activation marker ICOS was similarly reduced in both CTLA-4 Ig-treated and anti-CD28 dAb-treated recipients relative to untreated controls (Figure 2E). In contrast, we observed no statistically significant difference in either CD44 or CD62L expression on graft-reactive CD $8^{+}$Thy $1.1^{+} \mathrm{T}$ cells isolated from CTLA-4 Ig-treated vs. anti-CD28 $\mathrm{dAb}$-treated animals (Figure $2 \mathrm{E}$ ). Moreover, we did not detect the emergence of Foxp $3^{+} \mathrm{CD} 8^{+} \mathrm{Thy} 1.1^{+} \mathrm{T}$ cells in either of the treatment groups (Supplemental Figure 2), suggesting that neither reagent promotes the differentiation of $\mathrm{CD} 8^{+}$Treg.

Because the findings above were generated using monoclonal T cell receptor (TCR) transgenic populations, we sought to confirm these results in the endogenous, polyclonal immune response to the transplant. In this experiment, endogenous memory $\mathrm{CD}^{+} \mathrm{T}$ cells elicited following Listeria-OVA infection were characterized as Thy $1.1^{-} \mathrm{CD} 11 \mathrm{a}^{\mathrm{hi}}(44)$. Expansion of endogenous $\mathrm{CD} 8^{+}$memory $\mathrm{T}$ cells in these recipients was assessed following skin transplantation using BrdU incorporation, which was administered to the animals on days 2 and 4 after skin graft rechallenge. Animals were treated with CTLA- 4 Ig or anti-CD28 dAb on days 0,2 , and 4 as described in Methods. Results indicated that the frequency of BrdU ${ }^{+}$Thy $1.1^{-} C D 11 a^{\text {hi }}$ endogenous $\mathrm{CD}^{+}$memory $\mathrm{T}$ cells on day 5 after skin graft rechallenge in the draining LN was similarly reduced in both CTLA-4 Ig-treated and anti-CD28 dAb-treated animals (Figure 2, F and G), again suggesting that CTLA-4 Ig and selective CD28 blockade do not differentially impact accumulation of donor-reactive $\mathrm{CD}^{+}$memory $\mathrm{T}$ cells following transplantation.

Neither CTLA-4 nor PD-L1 signals negatively regulate CD8+ memory $T$ cell accumulation in the presence of CD28 blockade. Conceptually, selective CD28 blockade might more potently inhibit $\mathrm{T}$ cell responses relative to CTLA-4 Ig because it leaves coinhibitory CTLA-4/B7 and PD-L1/CD80 interactions intact $(25,45)$. Our previous results in studies of primary $\mathrm{CD} 8^{+} \mathrm{T}$ cell responses revealed that blocking CTLA4/B7 interactions resulted in reduced ability of anti-CD28 dAb to inhibit primary graft-reactive CD ${ }^{+}$ $\mathrm{T}$ cell responses, but that PD-L1/CD80 interactions were dispensable for this effect (41). Here, we tested whether disruption of CTLA-4/B7 and/or PD-L1/CD80 interactions impacted the efficacy of selective CD28 blockade in inhibiting memory $\mathrm{CD}^{+} \mathrm{T}$ cell accumulation. Groups of mice containing graft-reactive Thy $1.1^{+} \mathrm{CD} 8^{+}$memory $\mathrm{T}$ cells received membrane-bound OVA (mOVA) skin grafts and were treated with anti-CD28 dAb alone or in the presence of blocking antibodies against CTLA-4 or $\mathrm{PD}-\mathrm{L} 1$. Results indicated that, in contrast to what is observed with primary CD8 ${ }^{+} \mathrm{T}$ cell responses (41), blocking CTLA-4 did not impact the efficacy of selective CD28 dAb in inhibiting CD8 $8^{+}$memory $\mathrm{T}$ cell accumulation in the draining LN by day 5 after transplant (Figure 3, A and B). Similarly, blocking PD-L1 also had no effect on anti-CD28 dAb efficacy. In addition, the ability of selective CD28 blockade to diminish ICOS upregulation on the surface of secondary effectors was also not dependent on preserved CTLA-4 or PD-L1 coinhibition (Figure 3C). Overall, these data show that accumulation of graft-reactive $\mathrm{CD}^{+}$secondary effectors following transplantation is independent of both the CTLA-4 and PD-L1 coinhibitory pathways. 
$\mathbf{A}$
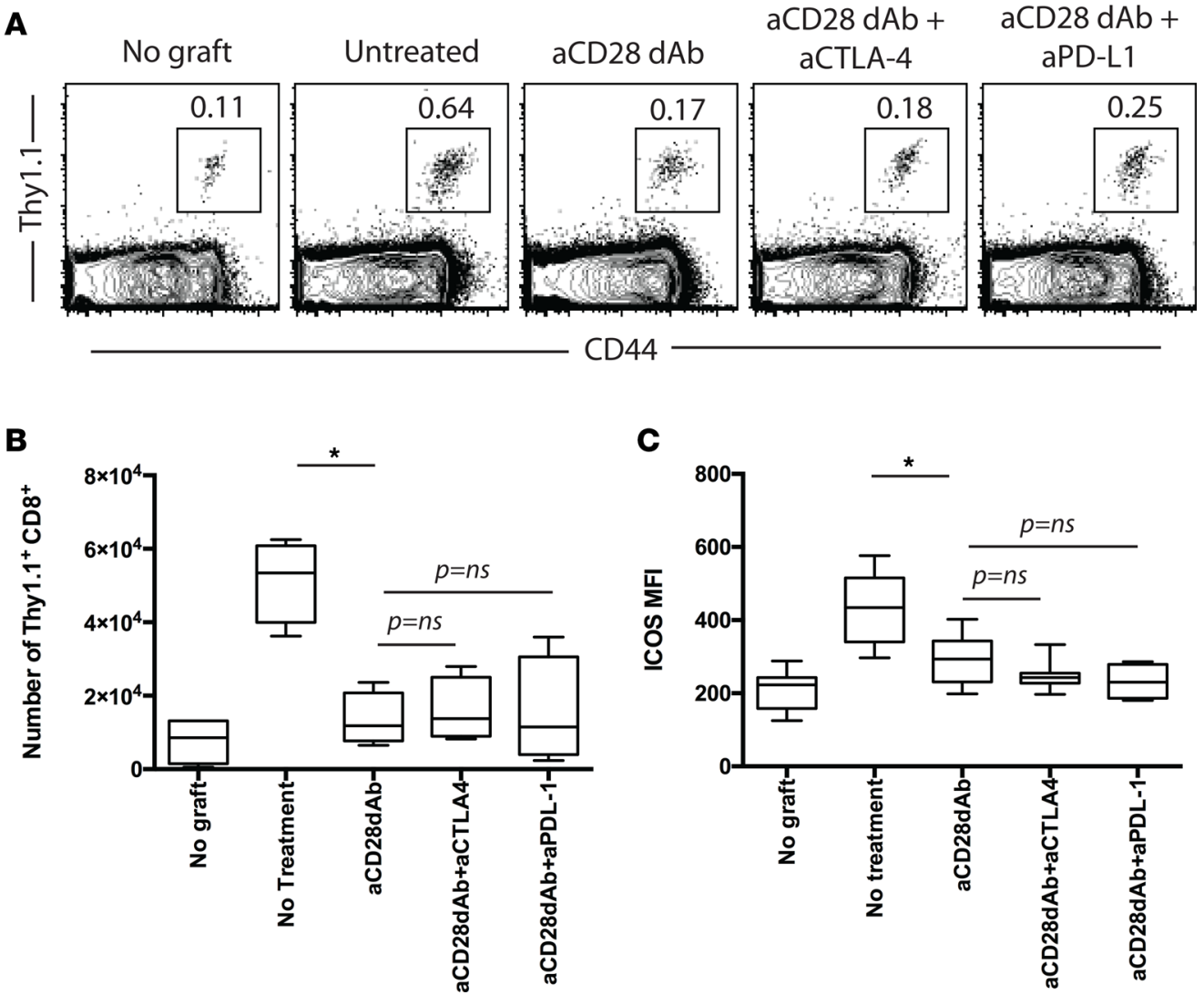

Figure 3. Neither CTLA-4 nor PD-L1 signals negatively regulate CD8+ memory T cell accumulation in the presence of CD28 blockade. Thy1.1+ $0 T-$ I T cells $\left(1 \times 10^{4}\right)$ were adoptively transferred into naive B6 Thy1.2 hosts and infected with Listeria-OVA to generate recipients containing memory OT-I T cells. On day 30 after infection, mice received an OVA-expressing skin graft and were treated with $100 \mu \mathrm{g}$ anti-CD28 dAb, $100 \mu \mathrm{g}$ anti-CD28 dAb $+250 \mu \mathrm{g}$ anti-CTLA-4, or $100 \mu \mathrm{g}$ anti-CD28 dAb $+250 \mu \mathrm{g}$ anti-PD-L1 on days 0,2 , and 4 after transplant. Animals were sacrificed on day 5 after transplant and graft-draining LN were harvested; the number of Thy1.1+ CD8 ${ }^{+}$T cells was quantified in (A) representative flow cytometry plots and (B) summary data of absolute number of CD8 ${ }^{+}$Thy $1.1^{+}$T cells per draining node. (C) MFI of ICOS expression on CD8 ${ }^{+}$Thy1.1 $1^{+} \mathrm{T}$ cells isolated from LN of mice in the indicated groups. Data shown in $\mathbf{B}$ and $\mathbf{C}$ are summary data of 2 independent experiments with 5-10 mice per group. ${ }^{*} P<0.05$ by 1-way ANOVA. dAb, domain antibody.

CTLA-4 controls CD8 $8^{+}$memory T cell/secondary effector cytokine secreting function. Given the data that selective CD28 blockade did not differentially alter expansion and accumulation of CD8 ${ }^{+}$memory $\mathrm{T}$ cell responses and that differential graft rejection was not due to differences in the magnitude of the endogenous response in these recipients, we next reasoned that selective CD28 blockade might differentially affect effector function during secondary recall responses. To test this, animals containing graft-reactive memory Thy $1.1^{+} \mathrm{CD} 8^{+} \mathrm{T}$ cells received OVA-expressing skin grafts and were treated with control dAb, CTLA-4 Ig, anti-CD28 dAb alone, or anti-CD28 dAb in the presence of blocking antibodies against CTLA-4. On day 5, spleen and draining LN were restimulated in vitro, and multicytokine-producing function was assessed. Results in both spleen and DLN were similar; thus, spleen only is shown in Figure 4 for brevity. In contrast to the effect on $\mathrm{T}$ cell accumulation, we observed that selective CD28 blockade better inhibited the acquisition of IFN- $\gamma$, TNF, and IL-2 production by secondary effectors following skin graft rechallenge. For example, while untreated animals demonstrated a surge in the frequency of $\mathrm{CD} 8^{+}$Thy $1.1^{+} \mathrm{IFN}-\gamma^{+} \mathrm{IL}-2^{+}$double producers relative to animals that did not receive a skin graft (Figure 4, A and C), those treated with CTLA-4 Ig failed to experience a reduction in the frequency of cytokine-producing effectors. In contrast, animals treated with anti-CD28 $\mathrm{dAb}$ demonstrated a significant reduction in the frequency and number of IFN- $\gamma$ single-positive secondary effectors (Figure 4C), IFN- $\gamma^{+}$IL- $2^{+}$double-positive effectors (Figure 4D), and IFN- $\gamma^{+} \mathrm{TNF}^{+}$double-positive effectors (Figure 4E). Importantly, administration of the CTLA-4 blocking antibody reversed these effects of anti-CD28 dAb, demonstrating that CTLA-4 coinhibitory function can modulate cytokine effector function of secondary $\mathrm{CD} 8^{+} \mathrm{T}$ cell responses. In contrast, anti-PD-L1 had no effect on the ability of selective CD28 blockade to potently attenuate donor-reactive memory $\mathrm{CD}^{+} \mathrm{T}$ cell cytokine function (data not shown). 

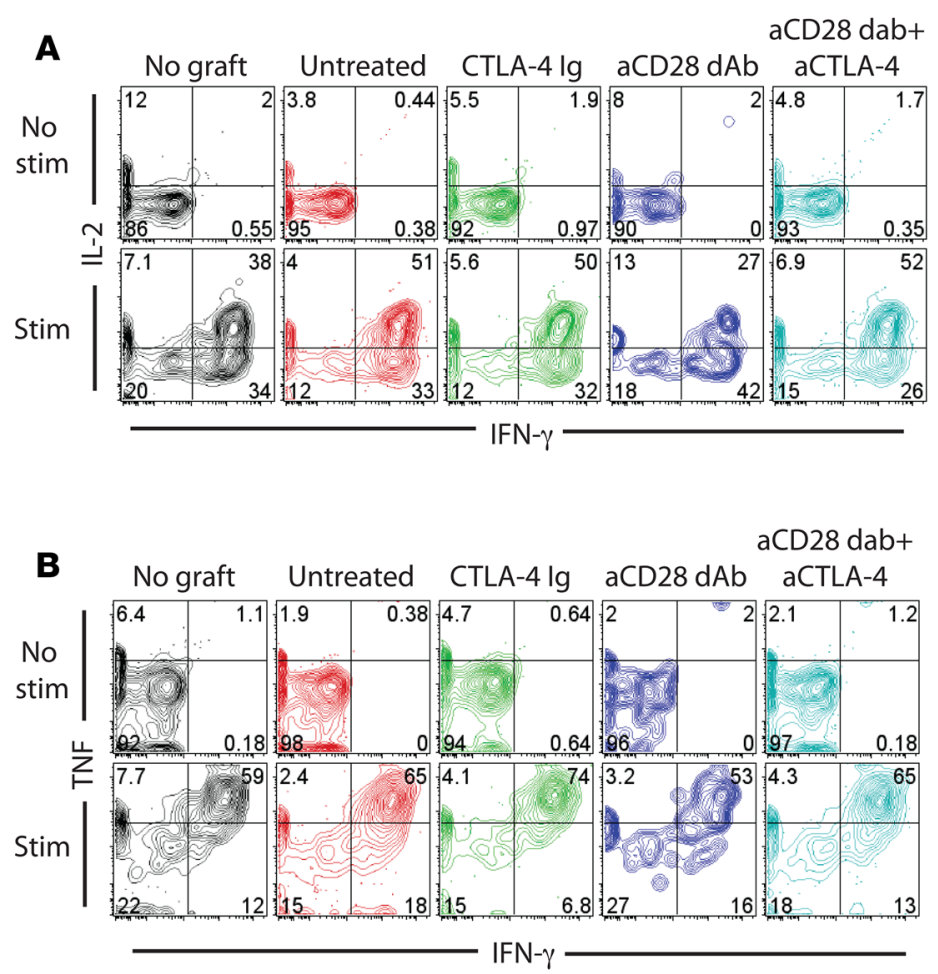

C

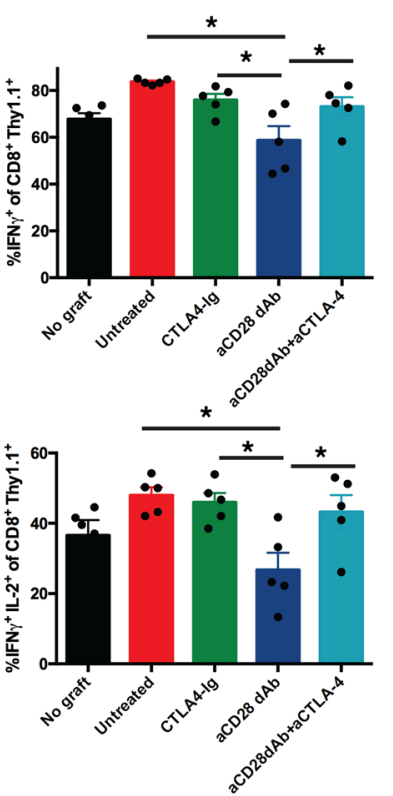

$\mathbf{E}$

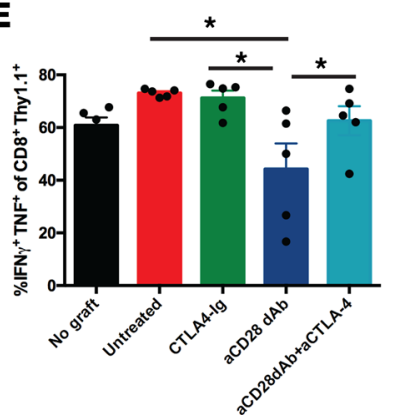

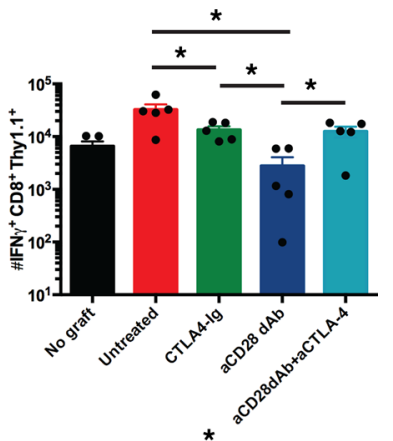
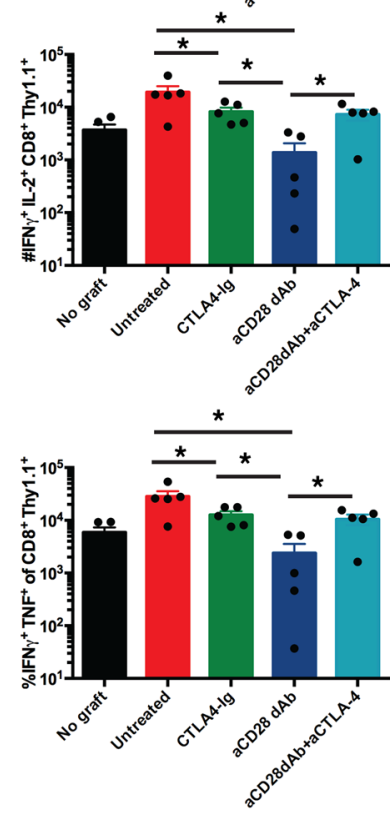

Figure 4. CTLA-4 coinhibitory signals control CD8+ memory T cell/secondary effector cytokine secreting function. Thy1.1+ 0 OT-I T cells $\left(1 \times 10^{4}\right)$ were adoptively transferred into naive B6 Thy1.2 hosts and infected with Listeria-OVA to generate recipients containing memory OT-I T cells. On day 30 after infection, mice received an OVA-expressing skin graft and were treated with $200 \mu \mathrm{g}$ CTLA-4 lg, $100 \mu \mathrm{g}$ anti-CD28 dAb, or $100 \mu \mathrm{g}$ anti-CD28 dAb + $250 \mu \mathrm{g}$ anti-CTLA-4 on days 0,2 , and 4 after transplant. Animals were sacrificed on day 5 after transplant, and splenocytes were harvested and restimulated in vitro with $10 \mathrm{nM}$ SIINFEKL as described in Methods. (A) Representative flow cytometry plots of IFN- $\gamma$ and IL-2 secretion from unstimulated (top row) and stimulated (bottom row) CD8 ${ }^{+}$Thy1.1 $1^{+}$T cells. (B) Representative flow cytometry plots of IFN- $\gamma$ and TNF secretion from unstimulated (top row) and stimulated (bottom row) CD8 ${ }^{+}$Thy1.1 $1^{+}$T cells. (C-E) Frequencies (left) and absolute numbers (right) of (C) IFN- $\gamma-$, (D) IFN- $\gamma^{+}$IL- $2^{+}-$, and (E) IFN- $\gamma^{+} \mathrm{TNF}^{+}-$producing CD8 ${ }^{+}$Thy $1.1^{+} \mathrm{T}_{\text {cells. }}$ Data are representative of 3 independent experiments with a total of $10-15$ mice per group. ${ }^{*} P<0.05$ by 1 -way ANOVA. dAb, domain antibody.

Selective CD28 blockade modulates recruitment of innate immune cells into allografts. Based on the observed differences in $\mathrm{T}$ cell cytokine production during secondary responses in animals treated with CTLA-4 Ig vs. anti-CD28 dAb, we hypothesized that these T cells may induce differential recruitment of immune cells into allografts. To test this, animals possessing OVA-specific memory T cells were grafted with OVA-expressing skin grafts and treated with PBS, CTLA-4 Ig, or anti-CD28 dAb, and grafts were harvested at days 5 and 10 after transplantation. As shown in Figure 5A, no differences in trafficking of OVA-specific Thy $1.1^{+}$secondary effectors into donor tissue were observed. This was true both on day 5 (Figure 5B) and day 10 (Figure 5C) after transplant. Furthermore, while there was no difference in the frequency of $\mathrm{CD} 11 \mathrm{~b}^{+}$ macrophages in grafts obtained from animals treated with CTLA-4 Ig on day 5 after transplant, the recruitment of $\mathrm{CD} 11 \mathrm{~b}^{+}$macrophages was significantly diminished in animals treated with selective CD28 blockade (Figure 5, D and E). By day 10 after transplant (Figure 5F), frequencies of $C D 11 b^{+}$cells were reduced in both the CTLA-4 Ig- and anti-CD28 dAb-treated groups relative to untreated animals; in addition, grafts isolated from anti-CD28 dAb-treated animals donors exhibited a further reduction in frequency of $\mathrm{CD} 11 \mathrm{~b}^{+}$infiltrating cells relative to grafts isolated from CTLA-4 Ig-treated animals. Frequencies of total Gr- $1^{+}$cells and $\mathrm{CD}^{-} \mathrm{CD} 11 \mathrm{~b}^{+} \mathrm{Gr}-1^{+}$myeloid-derived suppressor cells (MDSC) within the allografts were not different between the CTLA-4 Ig-treated and anti-CD28 dAb-treated animals (Supplemental Figure 3). Taken together, these results suggest that the differential cytokine-secreting capacity of $\mathrm{CD} 8^{+}$secondary 
A

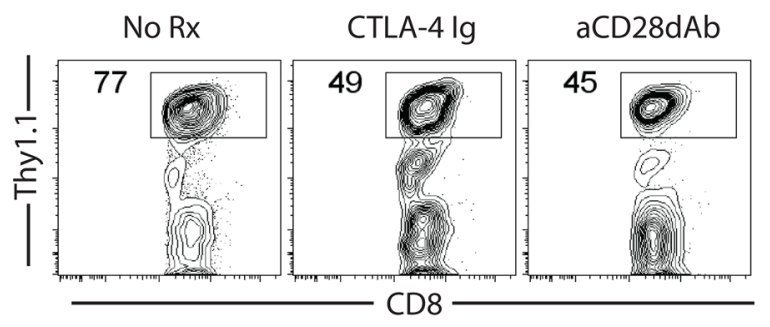

D

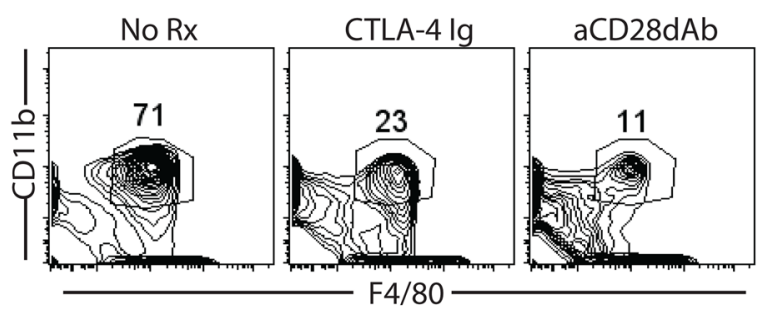

B

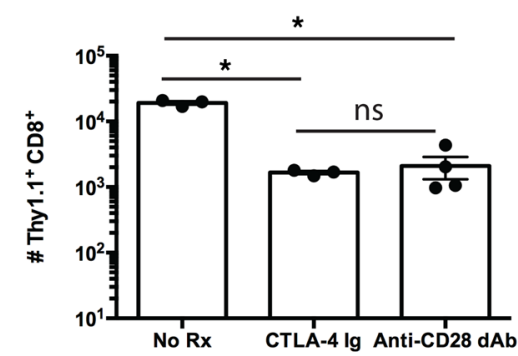

C Day 10

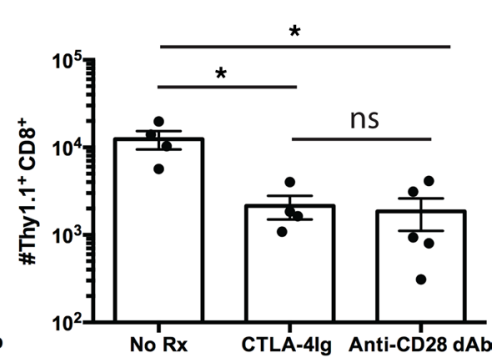

$\mathbf{E}$

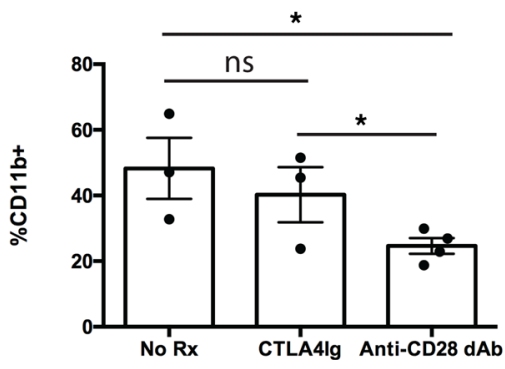

$\mathbf{F}$

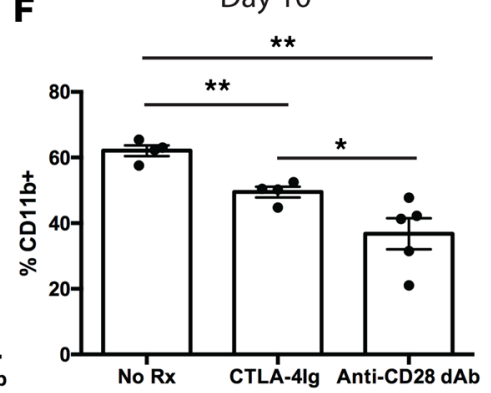

Figure 5. Selective CD28 blockade modulates recruitment of innate immune cells into allografts. Thy1.1+ OT-I T cells $\left(1 \times 10^{4}\right)$ were adoptively transferred into naive B6 Thy1.2 hosts and infected with Listeria-OVA to generate recipients containing memory OT-I T cells. (A-D) On day 30 after infection, mice received an OVA-expressing skin graft and were treated with $200 \mu \mathrm{g}$ CTLA-4 Ig or $100 \mu \mathrm{g}$ anti-CD28 dAb on days 0, 2, and 4 after transplant. Animals were sacrificed on days 5 or 10 after transplant, and skin grafts were harvested and processed for graft-infiltrating leukocytes. (A) Representative flow cytometry plots depicting frequencies of Thy $11^{+} T$ cells infiltrating skin grafts (data are gated on CD8 ${ }^{+} \mathrm{T}$ cells) on day 5 . (B and $\mathbf{C}$ ) Summary data of absolute numbers of graft-infiltrating Thy1.1 $1^{+}$T cells on day 5 (B) and day 10 (C) after transplant. (D) Representative flow cytometry plots of frequencies of CD11 b myeloid cells infiltrating skin grafts on day 5 , summarized as absolute numbers of cells on day $5(\mathbf{E})$ and day $10(\mathbf{F}) .{ }^{*} P<0.05,{ }^{* *} P<0.01$ by 1 -way ANOVA. dAb, domain antibody.

effectors in the presence of CTLA-4 Ig vs. anti-CD28 dAb may result in differential recruitment of innate immune cells that function to further enhance inflammation.

Inhibition of IFN- $\gamma$-and TNF-mediated signals significantly impairs recruitment of $C D 11 b^{+}$myeloid cells into rejecting allografts and delays graft rejection. In order to test whether decreased secretion of effector cytokines IFN- $\gamma$ and TNF observed during secondary recall responses of animals treated with selective CD28 blockade is causally related to the reduced $\mathrm{CD} 11 \mathrm{~b}^{+}$infiltration observed in these animals, we queried whether in vivo blockade of IFN- $\gamma$ and TNF could prevent the influx of $\mathrm{CD}_{11 \mathrm{~b}^{+}}$myeloid cells into transplanted donor tissue observed in the setting of CTLA-4 Ig and thereby delay or prevent rejection. Groups of animals containing OVA-specific memory $\mathrm{CD}^{+} \mathrm{T}$ cells were grafted with OVA-expressing skin transplants and treated with PBS, CTLA-4 Ig alone, or CTLA-4 Ig in the presence of blocking antibodies to IFN- $\gamma$ and TNF (clones R4-6A2 and XT3.11, respectively) (Figure 6A). Results indicated that the frequency and absolute number of $\mathrm{CD} 11 \mathrm{~b}^{+}$macrophages was significantly reduced both on day 5 and day 10 after transplant when IFN- $\gamma$ and TNF signals were blocked (Figure 6, B and C). Moreover, while animals in both groups eventually rejected their grafts, the addition of blocking antibodies against IFN- $\gamma$ and TNF significantly delayed rejection such that the number of animals with surviving grafts on day 21 after transplant was significantly increased in the group treated with CTLA-4 Ig and the cytokine blocking antibodies vs. the group treated with CTLA-4 Ig alone ( $P=0.03$, Figure $6, \mathrm{D}$ and $\mathrm{E})$. Thus, these data demonstrate that elaboration of IFN- $\gamma$ and TNF causally contribute to allograft rejection in this model and - taken together with data in Figure 5, D-F - suggest that the superior efficacy of selective CD28 blockade is at least partially dependent on its ability to impair effector cytokine secretion from secondary effectors.

\section{Discussion}

The data presented here show that $\mathrm{CD}^{+}$memory $\mathrm{T}$ cell responses are modulated by $\mathrm{CD} 28$ signals. While many studies (including our own) have shown that memory $\mathrm{T}$ cells have a reduced requirement for CD28 relative to naive $\mathrm{T}$ cells, and in many case can still mediate rejection of an allograft despite CD28 blockade, almost all of these studies reveal that memory $\mathrm{T}$ cells are at least somewhat impacted by a loss of CD28 signals 
A

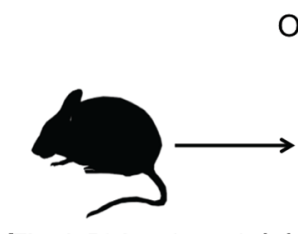

Thy $1.2^{+}$host containing OVA-specific Thy $1.1^{+}$ memory CD8 ${ }^{+}$T cells
OVA-expressing

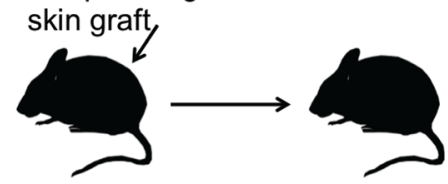

Treated with CTLA-4

$\mathrm{Ig}+$ anti-IFN- $y$ and

anti-TNF on days 0,2 ,

4,6
B

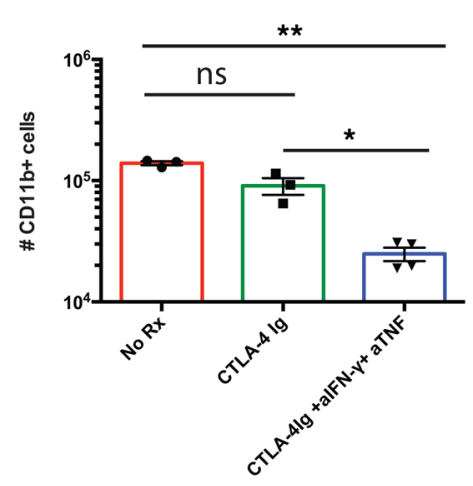

C Day 10

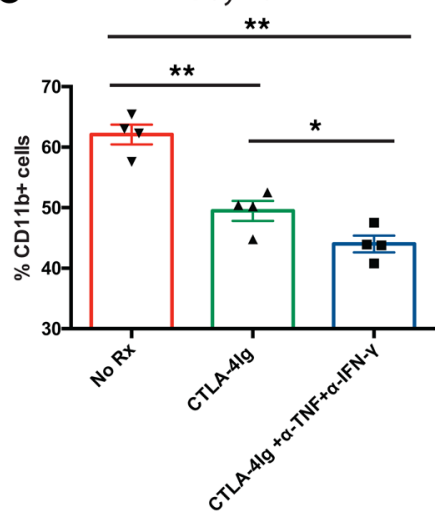

D

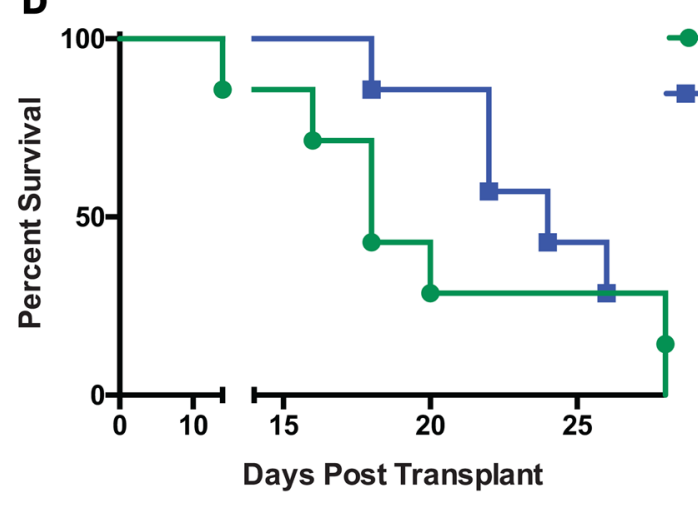

E

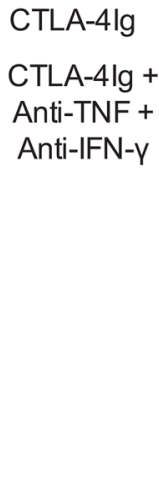

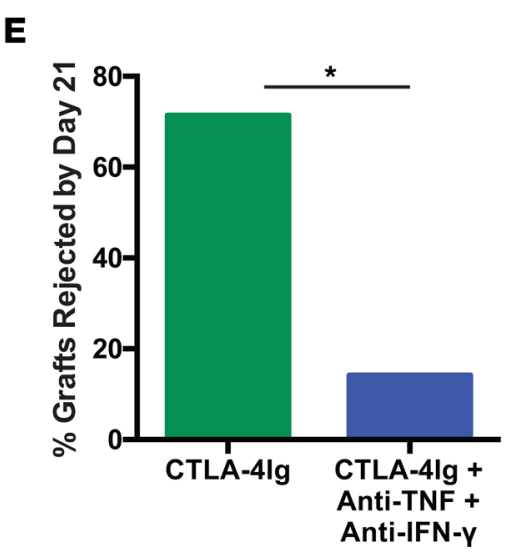

Figure 6. Inhibition of IFN- $\gamma$ - and TNF-mediated signals significantly impairs recruitment of CD11b+ myeloid cells into rejecting allografts and delays graft rejection. (A) Experimental design for experiments in which recipients containing memory OT-I T cells generated as above received an OVA-expressing skin graft and were treated with either nothing, CTLA-4 Ig alone, or CTLA-4 Ig and $250 \mu \mathrm{g}$ of anti-IFN- $\gamma$ and anti-TNF as described in Methods. (B and C) Summary data of absolute numbers of graft-infiltrating CD11 b ${ }^{+}$T cells in the 3 groups on day 5 (B) and 10 (C) after transplant. Data shown are $n=5$ mice/group, representative of 2 independent experiments with a total of 10 mice per group. ${ }^{*} P<0.05,{ }^{* *} P<0.01$ by 1 -way ANOVA. (D) Graft survival data of mice treated as above. Kaplan-Meier survival curve of mice treated as above. $n=7 / g r o u p$. (E) Survival frequencies of allografts in CTLA-4 Ig- vs. CTLA-4 Ig + anti-TNF + anti-IFN- $\gamma$-treated animals on day 21 after transplant. ${ }^{*} P=0.03$ by $\chi^{2}$ analysis of frequencies of surviving grafts. dAb, domain antibody.

(46-48). In this study, we show that both CTLA-4 Ig and anti-CD28 dAb similarly and significantly reduced the expansion and accumulation of donor-reactive $\mathrm{CD} 8^{+} \mathrm{T}$ cells. This was true for both TCR transgenic cells responding to a defined OVA antigen and for endogenous graft reactive cells, as defined by CD11 $\mathrm{a}^{\text {hi }}$ and $\mathrm{BrdU}^{+}$ status. Thus, these data show that regulation of the proliferative capacity of memory $\mathrm{T}$ cells and secondary effectors is controlled at least in part by CD28 signals. These data are in contrast to very early in vitro studies that suggested that memory $\mathrm{CD} 8^{+} \mathrm{T}$ cells function independently of $\mathrm{CD} 28$, and they are supported by more recent in vivo studies in models of viral infection that demonstrated that expansion of secondary effectors was diminished in CTLA-4 Ig-treated mice or was diminished when memory $\mathrm{CD} 8^{+} \mathrm{T}$ cells were adoptively transferred into CD80/CD86 double-KO hosts (46-48). These studies showed that, similar to its role in naive $\mathrm{T}$ cells, $\mathrm{CD} 28$ signaling in memory $\mathrm{CD} 8^{+} \mathrm{T}$ cells resulted in increased expression of $\mathrm{Bcl}-\mathrm{xL}$ and increased antigen-specific $\mathrm{CD} 8^{+} \mathrm{T}$ cell accumulation (47). Moreover, our studies are consistent with a recent study using the FR104 selective CD28 blocker, which demonstrated that selective CD28 blockade effectively controlled tuberculin-directed memory T cell responses in NHPs (49).

On the other hand, we found that CTLA-4 Ig administered during the recall response alone had no effect on the frequency of IFN- $\gamma$ and IL-2 cytokine-producing secondary effectors, suggesting that control of cytokine secretion in $\mathrm{CD} 8^{+}$memory $\mathrm{T}$ cells is not mediated solely by CD28 signals. Previous studies have not examined impact of CD28 signals on cytokine-secreting functionality; however, some have demonstrated that cytolytic function upon secondary recall is independent of CD28 (47). Here, we show that cytokine effector function in $\mathrm{CD} 8^{+}$memory $\mathrm{T}$ cells is potently regulated by the balance of $\mathrm{CD} 28$ and CTLA-4 signals, in that antagonism of CD28 while CTLA-4 signals are preserved results in significantly 
reduced secretion of IFN- $\gamma$ and TNF. These results highlight an important role for CTLA-4 coinhibitory signaling in attenuating secondary effector cytokine production. In contrast, CTLA-4 coinhibition was dispensable for the ability of selective CD28 dAb to reduce secondary effector expansion and accumulation following transplantation (Figure 3). These results are therefore in contrast with previous studies that found a potent coinhibitory role for CTLA- 4 in inhibiting proliferation of CD2 $8^{\text {null }} \mathrm{CD} 8^{+}$memory T cells (30). This discrepancy may be related to the distinct differentiation state of CD28 $8^{\text {null }}$ memory $\mathrm{T}$ cells as compared with the CD28 ${ }^{+}$memory $\mathrm{T}$ cells analyzed in this study and, thus, suggests a differential role for CTLA-4-mediated coinhibition in these populations.

The impact of selective CD28 blockade on memory $\mathrm{CD}^{+} \mathrm{T}$ cell cytokine function may be critical to allograft survival because it has been shown that donor-reactive $\mathrm{CD} 8^{+}$memory $\mathrm{T}$ cells infiltrate allografts within hours and amplify early posttransplant inflammation by producing IFN- $\gamma$ (50). Consistent with this, our data show that reduced effector cytokine secretion in the presence of selective CD28 blockade was associated with reduced innate inflammatory cell influx into allografts. Frequencies of $\mathrm{CD} 3^{-} \mathrm{CD} 11 \mathrm{~b}^{+} \mathrm{Gr}-\mathrm{1}^{+} \mathrm{MDSC}$ (51) were not different between CTLA-4 Ig-treated and anti-CD28 dAb-treated animals, in contrast with a previous study that identified an increase in CD11 $\mathrm{b}^{+}$MDSC in animals treated with selective CD28 blockade in a rat transplant model $(52,53)$. We posit that the differences in models and reagents used in this study and ours (i.e., rat vs. mouse, skin vs. kidney) may underlie these disparate results. Nevertheless, our data show that pairing CTLA-4 Ig with blockade of IFN- $\gamma$ and TNF in vivo recapitulates the reduced innate immune infiltration observed under selective CD28 blockade and significantly delays allograft rejection. Taken together, these data put forth a model in which the improved allograft survival observed in recipients bearing donor-reactive memory $\mathrm{CD}^{+} \mathrm{T}$ cells treated with selective CD28 blockade vs. CTLA-4 Ig is due to diminished inflammatory cytokine secretion in the presence of preserved CTLA- 4 coinhibitory signals, which in turn results in diminished innate cell recruitment and prolonged allograft survival. These findings do not preclude, of course, the possibility that other cell types can both make and respond to IFN- $\gamma$ and TNF signals in this model.

It is important to note that, while both skin graft and pathogen priming methods of eliciting donor-reactive memory showed increased efficacy of selective CD28 blockade over CTLA-4 Ig, the model in which donor-reactive memory $\mathrm{CD}^{+} \mathrm{T}$ cells are elicited via a prior pathogen infection required adjunct immunosuppression (VLA-4 antagonism) in order to illuminate a difference in skin graft survival between anti-CD28 $\mathrm{dAb}-$ and CTLA-4 Ig-treated recipients. First, these data demonstrate differences in the quantity and quality of donor-reactive memory $\mathrm{CD}^{+} \mathrm{T}$ cells elicited via distinct types of exposure and highlight the fact, as we previously reported (31), that the heterogeneity of alloreactive $\mathrm{CD} 8^{+} \mathrm{T}$ cell memory might necessitate tailored therapeutic targeting for optimal control. We previously showed that antagonism of either LFA-1 or VLA-4 synergized with a regimen consisting of CTLA-4 Ig and anti-CD154 to prolong survival in animals possessing donor-specific $\mathrm{CD}^{+}$memory $\mathrm{T}$ cells elicited via the Listeria-OVA system used here (54). We now report that anti-CD28 dAb is effective at prolonging graft survival in this model in the absence of CD154 antagonism, a finding that is highly clinically relevant in that progress of CD154 blockers in the translational pipeline has been slow and the path to FDA approval for these reagents is currently uncertain (55). Why is anti-VLA-4 required in this regimen? Based on our previous findings that VLA-4 antagonism reduced memory $\mathrm{CD}^{+} \mathrm{T}$ cell infiltration into allografts (43) coupled with a plethora of published studies in mouse models of multiple sclerosis and in human MS patients showing that anti-VLA-4 mAb (natalizumab) reduces effector influx across the blood-brain barrier (56), we posit that VLA-4 antagonism is synergistic with anti-CD28 $\mathrm{dAb}$ because it reduces the number of memory T cells entering into the allograft, while anti-CD28dAb limits the effector function of the cells once there. However, the potential for translation of this combination for use in clinical transplantation is also not clear, as chronic administration of VLA-4 antagonists has been associated with a risk of progressive multifocal leukoencephalopathy (57); further investigation is required in order to determine the clinical utility of this as a therapeutic target in transplantation.

In sum, the data presented here suggest that selective CD28 blockers may exhibit increased efficacy in inhibiting donor-reactive memory $\mathrm{CD}^{+} \mathrm{T}$ cell responses in transplant patients relative to belatacept, an attribute that could potentially lead to reduced incidence of acute rejection as compared with what has been observed in patients treated with belatacept. This notion is supported by recent evidence from both the NHP renal allograft model and human kidney transplant recipients showing that increased frequencies of $\mathrm{CD}_{2} 8^{+}$ effector memory $\mathrm{T}$ cells $\left(\mathrm{T}_{\mathrm{EM}}\right)$ were associated with increased risk of acute rejection $(24,58)$. Thus, in contrast with earlier suggestions that $\mathrm{CD} 28^{\text {null }}$ memory $\mathrm{T}$ cells were the mediators of belatacept-resistant rejection, these new data suggest that less differentiated memory $\mathrm{T}$ cells that retain expression of CD28 may underlie 
these rejection episodes (59), and therefore that CD28 may indeed still be an important therapeutic target in this cell population in order to limit acute rejection mediated by memory $\mathrm{T}$ cells and improve long-term outcomes following transplantation. Importantly, a recent study of FR104, another selective CD28 blocker, in healthy subjects showed the reagent was well tolerated and efficacious in limiting primary immune responses to keyhole limpet hemocyanin in vivo (60). Thus, further studies of the ability of selective CD28 blockade to inhibit donor-reactive memory $\mathrm{T}$ cell responses in NHPs, which possess $\mathrm{CD} 28^{\text {null }}$ populations at frequencies similar to those found in humans, are warranted.

\section{Methods}

Mice. C57BL/6 $\left(\mathrm{H}-2^{\mathrm{b}}\right)$ mice were obtained from the National Cancer Institute (Frederick, Maryland, USA). OT-I (61) and OT-II (62) transgenic mice, purchased from Taconic Farms, were bred to Thy1.1 background at Emory University. mOVA mice (C57BL/6 background, H-2 ${ }^{b}$ ) (63) were a gift from Marc Jenkins (University of Minnesota, Minneapolis, Minnesota, USA). All animals were housed in pathogen-free animal facilities at Emory University.

In vitro $T$ cell stimulation and measurement of CTLA-4 expression. In vitro-activated memory $\mathrm{T}$ cells were generated as per the published protocol of van der Windt et al. (42). Briefly, $3 \times 10^{6}$ splenocytes/well were plated in R10 into a 24 -well plate $\left(1.5 \mathrm{ml} /\right.$ well) and stimulated with $1 \mathrm{nM} \mathrm{OVA}_{257-264}$ (SIINFEKL) peptide and $10 \mathrm{nM}$ IL-2 for 4 days.

After 4 days, cultures were subjected to Ficoll (Mediatech) gradient centrifugation and rested in 10 $\mathrm{ng} / \mathrm{ml}$ IL-15 for 48 hours. For assessment of kinetics of CTLA-4 upregulation, $5 \times 10^{5}$ OT-I memory T cells were restimulated with $5 \times 10^{5} \mathrm{~B} 6 \mathrm{APC}$ and $1 \mathrm{nM}$ SIINFEKL. Control naive OT-I splenocytes were plated at $1 \times 10^{6} /$ well and stimulated with $1 \mathrm{nM}$ SIINFEKL. Cultures were harvested at 1, 2, 4, 24, and 48 hours after stimulation, and anti-CTLA- 4 Abs and isotype control Abs were added to the culture at 2 hours before harvesting.

Donor-reactive T cell adoptive transfers and Listeria infection. For adoptive transfers of donor-reactive T cells, spleen and mesenteric LNs isolated from Thy $1.1^{+}$OT-I mice were processed and stained with monoclonal antibodies for CD4 and CD8 (both from Invitrogen), Thy1.1, and Va2 (BD Pharmingen) for flow cytometry analysis. Cells were resuspended in PBS, and $1 \times 10^{4}$ of Thy1.1+ OT-I were injected i.v. $24-48$ hours prior to inoculation with $1 \times 10^{4} \mathrm{CFU}$ of Listeria monocytogenes-OVA (64) by i.p. injection. As we have previously published (6), frequencies of $\mathrm{CD}^{+}$Thy $1.1^{+}$OVA-specific memory $\mathrm{T}$ cells averaged $\sim 1 \%$ on day 30 after infection.

Skin transplantation and in vivo costimulatory molecule blockade. On day 30 after Listeria infection, full-thickness tail and ear skins were transplanted onto dorsal thorax of recipient mice and secured with adhesive bandages as previously described (65). As previously published, skin graft rejection in this model is dependent on donor-reactive Thy $1.1^{+}$memory $\mathrm{CD}^{+} \mathrm{T}$ cells because administration of an anti-Thy1.1 depleting antibody eliminated the rejection response (31). Mice were randomized to the different treatment arms, and batches of transplants in the different treatment arms were performed concurrently. Where indicated, mice

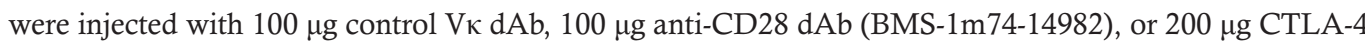
Ig (abatacept) (all Bristol-Myers Squibb) on days 0, 2, 4, and 6 three times per week continuously thereafter until the mice were sacrificed or until day 50 (for skin graft survival experiments). Generation of BMS1m74-14982 anti-CD28 dAb was previously described in ref. 41. Reagent dosing was based on molecular weight (93 kDa for CTLA-4 Ig vs. 52kDa for anti-CD28 dAb), serum half-life (96 hours for CTLA-4 Ig vs. 28 hours for anti-CD28 dAb), and murine mixed lymphocyte reaction $50 \%$ effective concentration $\left(\mathrm{EC}_{50}\right)$ $(4.25 \pm 2.0 \mathrm{nM}$ for CTLA-4 Ig vs. $2.20 \pm 0.6 \mathrm{nM}$ for anti-CD28 dAb) as originally described (41).

In some experiments, mice were also treated with $250 \mu \mathrm{g}$ monoclonal rat anti-mouse VLA-4 (clone PS/2, BioXCell) on days 0, 2, 4, and 6. For CTLA-4 and PD-L1 studies, grafted recipients were treated with a short course of $100 \mu \mathrm{g}$ of anti-CD28 dAb on days 0,2 , and 4 and sacrificed on day 5 or day 10 after transplant as indicated. Where indicated, mice also received either $500 \mathrm{~g}$ of anti-CTLA-4 (clone 9H10) or anti-PD-L1 (clone 10F.9G2) on days 0, 2, and 4. For IFN- $\gamma$ /TNF studies, mice received CTLA-4 Ig in the presence of 250 $\mu \mathrm{g}$ of anti-IFN- $\gamma$ (clone R4-6A2) or anti-TNF (clone XT3.11) on days 0, 2, and 4 (all from BioXCell).

Flow cytometry and intracellular cytokine staining. Spleens or graft-draining axillary and brachial LNs were stained for CD4 and CD8 (both from Invitrogen) and Thy1.1 (BD Pharmingen). In some experiments, cells were also surface stained with anti-ICOS (BD Pharmingen). Absolute numbers were calculated using TruCount bead analysis according to the manufacturer's instructions (BD Biosciences). For intracellular 
cytokine staining, splenocytes were stimulated with $10 \mathrm{nM} \mathrm{OVA}_{257-264}$ (SIINFEKL) (Genscript Inc.) where indicated, in the presence of $10 \mu \mathrm{g} / \mathrm{ml}$ Brefeldin A (BD Pharmingen) for 4 hours. An intracellular staining kit (BD Pharmingen) was used to detect IFN- $\gamma$, TNF, and IL-2 (all from BD Pharmingen), according to manufacturer's instructions. Samples were analyzed on an LSRII flow cytometer (BD Biosciences). Data was analyzed using FlowJo software (Treestar Inc.).

BrdU assay. Mice that had received Listeria-OVA infections and generated a population of memory OT-I T cells were challenged with OVA-expressing skin grafts. On days 1 and 3 after transplant, mice were injected i.p. with $1 \mathrm{mg} \mathrm{BrdU}$ (MilliporeSigma) in $0.2 \mathrm{ml}$ PBS. On day 5, mice were sacrificed and intracellular BrdU+ OT-I T cells in the graft-draining LN were quantified using a BrdU Flow Kit (BD Pharmingen).

Graft-infiltrating cell analysis. For analysis of graft-infiltrating leukocytes, skin grafts were harvested at day 5 after transplantation and washed with $1 \times$ PBS. Grafts were placed in a 24-well plate containing $0.5 \mathrm{ml} /$ well digestion buffer (HBSS with $\mathrm{Ca}^{+2}$ and $\mathrm{Mg}^{+2}$ plus $2 \mathrm{mg} / \mathrm{ml}$ collagenase P; MilliporeSigma) and chopped into fragments of $0.5-2 \mathrm{~mm}^{3}$. An additional $1 \mathrm{ml}$ digestion buffer was added to the well, and skin fragments were incubated for 30 minutes at $37^{\circ} \mathrm{C}$. Digested graft fragments were then homogenized lightly with a $5-\mathrm{ml}$ syringe plunger on a $70-\mu \mathrm{M}$ strainer. Cells were then rinsed, washed, passed through a $40-\mu \mathrm{M}$ strainer, and resuspended in FACS buffer for staining.

Statistics. Survival data were plotted on Kaplan-Meier curves, and log-rank tests were performed. For analysis of T cell responses, nonparametric 1-way ANOVA with Dunn's post-tests were performed. In all figures, data are represented as the mean \pm SEM. Results were considered significant if $P<0.05$. Graft survival on day 21 after transplant was compared using $\chi^{2}$ analysis. All analyses were done using GraphPad Prism software. In all legends and figures, ${ }^{*} P<0.05,{ }^{* *} P<0.01,{ }^{* * *} P<0.001$.

Study approval. All animals were maintained and used ethically in accordance with Emory University IACUC guidelines, and experiments were conducted under IACUC study approval DAR-2003254-091418GN.

\section{Author contributions}

MLF designed the study, analyzed the data, and wrote the manuscript. DL conducted experiments and acquired and analyzed data. IRB designed experiments, analyzed data, and edited the manuscript.

\section{Acknowledgments}

This study was supported by NIH grants AI104699 and AI073707 to MLF. Abatacept and anti-CD28 dAb were provided by Steven G. Nadler of Bristol-Myers Squibb. The authors would also like to thank Andrew Adams and members of the Ford Lab for helpful discussions.

Address correspondence to: Mandy L. Ford, 101 Woodruff Circle, Woodruff Memorial Research Building, Suite 5105, Emory University, Atlanta, Georgia 30322, USA. Phone: 404.727.2900; Email: mandy.ford@emory.edu.

1. Vincenti F, et al. Belatacept and Long-Term Outcomes in Kidney Transplantation. N Engl J Med. 2016;374(4):333-343.

2. Vincenti F, et al. Costimulation blockade with belatacept in renal transplantation. N Engl J Med. 2005;353(8):770-781.

3. Valujskikh A. Memory T cells in allograft rejection. Adv Exp Med Biol. 2007;601:247-256.

4. Benichou G, Gonzalez B, Marino J, Ayasoufi K, Valujskikh A. Role of Memory T Cells in Allograft Rejection and Tolerance. Front Immunol. 2017;8:170.

5. Krummey SM, Ford ML. Heterogeneity within T Cell Memory: Implications for Transplant Tolerance. Front Immunol. 2012;3:36.

6. Floyd TL, et al. Limiting the amount and duration of antigen exposure during priming increases memory $\mathrm{T}$ cell requirement for costimulation during recall. J Immunol. 2011;186(4):2033-2041.

7. Adams AB, Pearson TC, Larsen CP. Heterologous immunity: an overlooked barrier to tolerance. Immunol Rev. 2003;196:147-160.

8. Adams $\mathrm{AB}$, et al. Heterologous immunity provides a potent barrier to transplantation tolerance. J Clin Invest. 2003;111(12):1887-1895.

9. Valujskikh A. The challenge of inhibiting alloreactive T-cell memory. Am J Transplant. 2006;6(4):647-651.

10. Valujskikh A, Lakkis FG. In remembrance of things past: memory T cells and transplant rejection. Immunol Rev. 2003;196:65-74.

11. Valujskikh A, Pantenburg B, Heeger PS. Primed allospecific T cells prevent the effects of costimulatory blockade on prolonged cardiac allograft survival in mice. Am J Transplant. 2002;2(6):501-509.

12. Zhai Y, Meng L, Gao F, Busuttil RW, Kupiec-Weglinski JW. Allograft rejection by primed/memory CD8+ T cells is CD154 blockade resistant: therapeutic implications for sensitized transplant recipients. J Immunol. 2002;169(8):4667-4673.

13. Floyd TL, et al. Limiting the amount and duration of antigen exposure during priming increases memory $\mathrm{T}$ cell requirement for costimulation during recall. J Immunol. 2011;186(4):2033-2041. 
14. Ford ML, Larsen CP. Overcoming the memory barrier in tolerance induction: molecular mimicry and functional heterogeneity among pathogen-specific T-cell populations. Curr Opin Organ Transplant. 2010;15(4):405-410.

15. Ford ML, Larsen CP. Transplantation tolerance: memories that haunt us. Sci Transl Med. 2011;3(86):86ps22.

16. Nadazdin O, et al. Phenotype, distribution and alloreactive properties of memory T cells from cynomolgus monkeys. Am $J$ Transplant. 2010;10(6):1375-1384.

17. Nadazdin O, et al. Host alloreactive memory T cells influence tolerance to kidney allografts in nonhuman primates. Sci Transl Med. 2011;3(86):86ra51.

18. Weaver TA, et al. Alefacept promotes co-stimulation blockade based allograft survival in nonhuman primates. Nat Med. 2009;15(7):746-749.

19. Lo DJ, et al. Selective targeting of human alloresponsive CD8+ effector memory T cells based on CD2 expression. Am J Transplant. 2011;11(1):22-33.

20. Lamb KE, Lodhi S, Meier-Kriesche HU. Long-term renal allograft survival in the United States: a critical reappraisal. Am J Transplant. 2011;11(3):450-462.

21. Lodhi SA, Lamb KE, Meier-Kriesche HU. Solid organ allograft survival improvement in the United States: the long-term does not mirror the dramatic short-term success. Am J Transplant. 2011;11(6):1226-1235.

22. Mou D, Espinosa J, Lo DJ, Kirk AD. CD28 negative T cells: is their loss our gain? Am J Transplant. 2014;14(11):2460-2466.

23. Winterberg PD, Ford ML. The effect of chronic kidney disease on T cell alloimmunity. Curr Opin Organ Transplant. 2017;22(1):22-28.

24. Cortes-Cerisuelo M, et al. Increased Pretransplant Frequency of CD28+ CD4+ TEM Predicts Belatacept-Resistant Rejection in Human Renal Transplant Recipients. Am J Transplant. 2017;17(9):2350-2362.

25. Ford ML, Adams AB, Pearson TC. Targeting co-stimulatory pathways: transplantation and autoimmunity. Nat Rev Nephrol. 2014;10(1):14-24

26. Wang CJ, et al. Cutting edge: cell-extrinsic immune regulation by CTLA-4 expressed on conventional T cells. J Immunol. 2012;189(3):1118-1122.

27. Walker LS, Sansom DM. The emerging role of CTLA4 as a cell-extrinsic regulator of T cell responses. Nat Rev Immunol. 2011;11(12):852-863.

28. Qureshi OS, et al. Trans-endocytosis of CD80 and CD86: a molecular basis for the cell-extrinsic function of CTLA-4. Science. 2011;332(6029):600-603.

29. Walunas TL, Bakker CY, Bluestone JA. CTLA-4 ligation blocks CD28-dependent T cell activation. J Exp Med. 1996;183(6):2541-2550.

30. Hoff $\mathrm{H}$, et al. Surface CD152 (CTLA-4) expression and signaling dictates longevity of CD28null T cells. J Immunol. 2009;182(9):5342-5351.

31. Badell IR, Kitchens WH, Wagener ME, Lukacher AE, Larsen CP, Ford ML. Pathogen Stimulation History Impacts Donor-Specific CD8(+) T Cell Susceptibility to Costimulation/Integrin Blockade-Based Therapy. Am J Transplant. 2015;15(12):3081-3094.

32. Vanhove B, et al. Selective blockade of CD28 and not CTLA-4 with a single-chain Fv-alpha1-antitrypsin fusion antibody. Blood. 2003;102(2):564-570.

33. Poirier N, Blancho G, Vanhove B. CD28-specific immunomodulating antibodies: what can be learned from experimental models? Am J Transplant. 2012;12(7):1682-1690.

34. Haanstra KG, et al. Selective blockade of CD28-mediated T cell costimulation protects rhesus monkeys against acute fatal experimental autoimmune encephalomyelitis. J Immunol. 2015;194(4):1454-1466.

35. Papotto $\mathrm{PH}$, et al. Novel CD28 antagonist mPEG PV1-Fab' mitigates experimental autoimmune uveitis by suppressing CD4+ T lymphocyte activation and IFN- $\gamma$ production. PLoS One. 2017;12(3):e0171822.

36. Zhang T, et al. Selective CD28 blockade attenuates acute and chronic rejection of murine cardiac allografts in a CTLA-4-dependent manner. Am J Transplant. 2011;11(8):1599-1609.

37. Poirier N, et al. Preclinical efficacy and immunological safety of FR104, an antagonist anti-CD28 monovalent Fab' antibody. Am J Transplant. 2012;12(10):2630-2640.

38. Poirier N, et al. FR104, an antagonist anti-CD28 monovalent fab' antibody, prevents alloimmunization and allows calcineurin inhibitor minimization in nonhuman primate renal allograft. Am J Transplant. 2015;15(1):88-100.

39. Ville S, et al. Anti-CD28 Antibody and Belatacept Exert Differential Effects on Mechanisms of Renal Allograft Rejection. $J$ Am Soc Nephrol. 2016;27(12):3577-3588.

40. Poirier N, et al. Inducing CTLA-4-dependent immune regulation by selective CD28 blockade promotes regulatory $\mathrm{T}$ cells in organ transplantation. Sci Transl Med. 2010;2(17):17ra10.

41. Liu D, et al. 2B4 (CD244) induced by selective CD28 blockade functionally regulates allograft-specific CD8+ T cell responses. J Exp Med. 2014;211(2):297-311.

42. van der Windt GJ, et al. CD8 memory T cells have a bioenergetic advantage that underlies their rapid recall ability. Proc Natl Acad Sci USA. 2013;110(35):14336-14341.

43. Kitchens WH, et al. Integrin antagonists prevent costimulatory blockade-resistant transplant rejection by CD8(+) memory $\mathrm{T}$ cells. Am J Transplant. 2012;12(1):69-80.

44. Butler NS, et al. Therapeutic blockade of PD-L1 and LAG-3 rapidly clears established blood-stage Plasmodium infection. Nat Immunol. 2011;13(2):188-195.

45. Butte MJ, Keir ME, Phamduy TB, Sharpe AH, Freeman GJ. Programmed death-1 ligand 1 interacts specifically with the B7-1 costimulatory molecule to inhibit T cell responses. Immunity. 2007;27(1):111-122.

46. Dolfi DV, et al. Dendritic cells and CD28 costimulation are required to sustain virus-specific CD8+ T cell responses during the effector phase in vivo. J Immunol. 2011;186(8):4599-4608.

47. Boesteanu AC, Katsikis PD. Memory T cells need CD28 costimulation to remember. Semin Immunol. 2009;21(2):69-77.

48. Borowski AB, et al. Memory CD8+ T cells require CD28 costimulation. J Immunol. 2007;179(10):6494-6503.

49. Poirier N, et al. Selective CD28 Antagonist Blunts Memory Immune Responses and Promotes Long-Term Control of Skin Inflammation in Nonhuman Primates. J Immunol. 2016;196(1):274-283. 
50. Schenk AD, Nozaki T, Rabant M, Valujskikh A, Fairchild RL. Donor-reactive CD8 memory T cells infiltrate cardiac allografts within 24-h posttransplant in naive recipients. Am J Transplant. 2008;8(8):1652-1661.

51. Yang R, Cai Z, Zhang Y, Yutzy WH, Roby KF, Roden RB. CD80 in immune suppression by mouse ovarian carcinoma-associated Gr-1+CD11b+ myeloid cells. Cancer Res. 2006;66(13):6807-6815.

52. Dugast AS, et al. Myeloid-derived suppressor cells accumulate in kidney allograft tolerance and specifically suppress effector $\mathrm{T}$ cell expansion. J Immunol. 2008;180(12):7898-7906.

53. Haspot F, et al. Anti-CD28 antibody-induced kidney allograft tolerance related to tryptophan degradation and TCR class II B7 regulatory cells. Am J Transplant. 2005;5(10):2339-2348.

54. Kitchens WH, et al. Integrin antagonists prevent costimulatory blockade-resistant transplant rejection by CD8(+) memory $\mathrm{T}$ cells. Am J Transplant. 2012;12(1):69-80.

55. Pinelli DF, Ford ML. Novel insights into anti-CD40/CD154 immunotherapy in transplant tolerance. Immunotherapy. 2015;7(4):399-410.

56. Schwab N, Schneider-Hohendorf T, Wiendl H. Therapeutic uses of anti- $\alpha 4$-integrin (anti-VLA-4) antibodies in multiple sclerosis. Int Immunol. 2015;27(1):47-53

57. Kitchens WH, Larsen CP, Ford ML. Integrin antagonists for transplant immunosuppression: panacea or peril? Immunotherapy. 2011;3(3):305-307.

58. Mathews DV, et al. Belatacept-Resistant Rejection Is Associated With CD28+ Memory CD8 T Cells. Am J Transplant. 2017;17(9):2285-2299.

59. Ville S, Poirier N, Blancho G, Vanhove B. Co-Stimulatory Blockade of the CD28/CD80-86/CTLA-4 Balance in Transplantation: Impact on Memory T Cells? Front Immunol. 2015;6:411.

60. Poirier N, et al. First-in-Human Study in Healthy Subjects with FR104, a Pegylated Monoclonal Antibody Fragment Antagonist of CD28. J Immunol. 2016;197(12):4593-4602.

61. Hogquist KA, Jameson SC, Heath WR, Howard JL, Bevan MJ, Carbone FR. T cell receptor antagonist peptides induce positive selection. Cell. 1994;76(1):17-27.

62. Barnden MJ, Allison J, Heath WR, Carbone FR. Defective TCR expression in transgenic mice constructed using cDNA-based alpha- and beta-chain genes under the control of heterologous regulatory elements. Immunol Cell Biol. 1998;76(1):34-40.

63. Ehst BD, Ingulli E, Jenkins MK. Development of a novel transgenic mouse for the study of interactions between CD4 and CD8 T cells during graft rejection. Am J Transplant. 2003;3(11):1355-1362.

64. Shen H, Miller JF, Fan X, Kolwyck D, Ahmed R, Harty JT. Compartmentalization of bacterial antigens: differential effects on priming of CD8 T cells and protective immunity. Cell. 1998;92(4):535-545.

65. Trambley J, et al. Asialo GM1(+) CD8(+) T cells play a critical role in costimulation blockade-resistant allograft rejection. J Clin Invest. 1999;104(12):1715-1722. 